\title{
Neuropsychological functioning of individuals with coca paste use disorder
}

\author{
Esperanza Vergara-Moragues ${ }^{\mathrm{a}}$, María Rocio Acosta Barreto ${ }^{\mathrm{b}}$, Sandra Santiago-Ramajo ${ }^{\mathrm{c}}$, \\ Diego Rivera $^{\mathrm{d}}$, Jennifer Alexandra Pardo Pachób ${ }^{\mathrm{b}}$, Francisco González-Saiz ${ }^{\mathrm{e}, \mathrm{f}}$ and Juan \\ Carlos Arango-Lasprilla ${ }^{\mathrm{g}, \mathrm{h}, \mathrm{i}}$
}

\begin{abstract}
aDepartamento de Psicobiología y Metodología en Ciencias del Comportamiento, Universidad Complutense de Madrid (UCM), Madrid, Spain;

bUniversidad de San Buenaventura, Bogotá, Colombia; 'Universidad Internacional de la Rioja (UNIR), Logroño, Spain;

${ }^{\mathrm{d} D e p a r t a m e n t o ~ d e ~ c i e n c i a s ~ d e ~ l a ~ S a l u d, ~ U n i v e r s i d a d ~ P u ́ b l i c a ~ d e ~ N a v a r r a, ~ P a m p l o n a, ~ E s p a n ̃ a ; ~}$ eUnidad de Salud Mental Comunitaria Villamartín, UGC Salud Mental, Área de Gestión Sanitaria Norte de Cádiz, Servicio Andaluz de Salud, Jerez de la Frontera, Spain;

f Instituto de Investigación e Innovación Biomédica de Cádiz (INiBICA), Cádiz, Spain;

gBiocruces Bizkaia Health Research Institute, Barakaldo, Spain;

hIKERBASQUE. Basque Foundation for Science, Bilbao, Spain;

iDepartment of Cell Biology and Histology, University of the Basque Country UPV/EHU, Leioa, Spain
\end{abstract}

This is an accepted manuscript of an article published by Taylor \& Francis in Addiction Research and Theory on 05 Oct 2020, available online:

https://doi.org/10.1080/16066359.2020.1825692 
Background: Cocaine use has increased worldwide in recent years. However, the specific effects of smoking coca paste and its consequences on the cognitive functioning of individuals are unknown. The purposes of this study were to compare the neuropsychological functioning of a group of 163 individuals with coca-paste use disorder (CPUD) to that of a group of 162 healthy controls (HC) and to examine the relationship between cognitive performance and sociodemographic characteristics of these groups. Methods: Participants were administered a comprehensive neuropsychological battery that included tests of learning and memory, language and executive functions. Results: Although there were no significant differences in age and educational level between the groups, individuals with CPUD had significantly lower cognitive performance on the tests of learning and memory, language and executive functions compared with HC. An interaction effect was observed between group (CPUD versus HC) and educational level in the cognitive domains of learning and memory and language, such that more years of education was associated with better performance in these domains only in the HC. Conclusions: Deficits in learning and memory, language and executive functions are common in individuals with CPUD. Cognitive rehabilitation programs have been shown to improve these functions in individuals with CPUD. Therefore, this study reinforces the necessity of including such programs as part of the holistic intervention plan for these individuals.

Keywords: Addiction; Neuropsychological Assessment; Learning; Memory; Language; Executive function. 


\section{Introduction}

The worldwide consumption and production of cocaine has increased in recent years, with Colombia being the main country producing cocaine (United Nations Office On Drugs and Crime [UNODC], 2019). The different ways in which cocaine is consumed could determine its pharmacokinetics and toxicity and, consequently, affect its addictive potential and possible effects on cognitive performance (Lizasoain, Moro, \& Lorenzo, 2002; Verdejo-García et al., 2012; Vonmoos et al., 2014). Smoking cocaine is one of the most addictive methods of administration. Coca paste (also colloquially referred to as "paco," "basuco" or "bazuco") and crack are the substances most commonly consumed via smoking, and although they are often confused, the production process and effects of these substances are different (López-Hill et al., 2011; Meikle et al., 2013; Pascale, Hynes, Cumsille, \& Bares, 2014; Parkin Daniels, 2015). Coca paste is the non-refined by-product that is derived from the initial extraction process from coca leaves and serves as a substrate for the elaboration of cocaine hydrochloride. In contrast, crack is produced during a later process that uses cocaine hydrochloride (Pascale et al., 2014; Prieto et al., 2015; Schwarzkopf, Lagos, Falconi, Scorza, \& Torterolo, 2018).

Coca paste is relatively easy to obtain illegally because of its lower cost compared to other substances, such as cocaine hydrochloride. As such, the consumption of coca paste is mostly concentrated in areas of low socio-economic status (Castaño, 2000; Fukushima et al., 2014; Galvalisi et al., 2015; Schwarzkopf et al., 2018), such as Latin American countries and especially Colombia, where it is one of the most frequently consumed illicit substances after marijuana and cocaine hydrochloride (ODC, 2017; UNODC, 2018). Today, there is no single standard formula, and consequently it is difficult to know the exact 
chemical composition of each product (Lopez-Hill et al., 2011; Meikle et al., 2013; Prieto et al., 2012; Sabogal-Carmona \& Urrego-Novoa, 2012; Schwarzkopf et al., 2018).

In general, for individuals who use cocaine, the initial administration of cocaine seems to improve cognitive functions (Spronk, Van Wel, Ramaekers \& Verkes, 2013). However, the long-term effects can cause cognitive impairment (Alonso-Matías, ReyesZamorano, González-Olvera, 2019). Neuroimaging studies have shown that people who abuse cocaine hydrochloride and crack may have structural differences and functional connectivity problems in the brain regions involved in cognition and emotion (Ashok, Mizuno, Volkow \& Howes, 2017; Alonso-Matías et al., 2019; Fernández-Serrano, PérezGarcía \& Verdejo, 2011; Orsini, Colon-Pérez, Heshmati. Setlow \& Febo, 2018). These findings are in accordance with studies of cognitive performance showing that cocaine hydrochloride and/or crack use disorders are frequently associated with impaired executive function, specifically inhibition, impulsiveness, working memory or decision making (Alonso-Matías et al., 2019; Czermainski et al., 2017; Fernández-Serrano et al., 2012; Verdejo et al., 2012; Vicario, Pérez-Rivas, Ladrón de Guevara-Miranda, Santín \& Sampedre-Piquero, 2020). In addition, these individuals have been shown to have other cognitive impairments in the areas of attention, memory and language (Alonso-Matías et al., 2019; Jovanovski \& Zakzanis, 2005; Kemmis et al., 2007; Vicario et al., 2020; Vonmoos et al., 2014). The short-and long-term cognitive deficits in individuals who use different substances, especially those who use cocaine variants such as coca paste, underscore the importance of investigating the cognitive functioning of these individuals and the need to develop cognitive rehabilitation interventions for this population (AlonsoMatías et al., 2019). 
Today, there is a lack of research on the effects of prolonged consumption of coca paste on cognitive performance and its relationship with sociodemographic characteristics of its consumers. Therefore, it is necessary to examine whether the neuropsychological impairment produced by the consumption of coca paste is similar to that produced by other drugs, such as cocaine hydrochloride and/or crack, in order to design adequate rehabilitation programs. Given the high prevalence of coca paste consumption and the importance of knowing the cognitive impairments in consumers, the purposes of the present study was to compare the neuropsychological functioning of a group of individuals with coca paste use disorder (CPUD) to that of a group of healthy controls (HC) and to examine the relationship between cognitive performance and the sociodemographic characteristics of these groups. Our general hypothesis was that individuals with CPUD would display significantly lower cognitive performance on tests of learning and memory, language and executive function compared to $\mathrm{HC}$, and number of years of education would not protect against this decline (Alonso-Matías et al., 2019; Czermainski et al., 2017; FernándezSerrano et al., 2012; Verdejo et al. 2012; Vicario et al., 2020). To the best of our knowledge, this is the first study to examine the neuropsychological functioning of individuals with CPUD.

\section{Material and methods}

\subsection{Participants}

The sample consisted of a total of 324 participants divided into two groups. The first group was composed of 162 Colombian adults who were admitted to different therapeutic communities in Bogotá for addiction treatment due to their CPUD (stimulant use disorder according to DSM 5 criteria). Patients from these communities received a comprehensive 
care program led by psychiatrists with the support of psychologists, occupational therapists and social workers for a duration of 3 months in an in-patient facility. To avoid short-term cognitive impairment related to coca paste intoxication, all participants in this group had been abstinent for at least 1 month before the assessment. The mean age at first substance consumption was $15.2(\mathrm{SD}=3.1)$ years old, and the mean consumption duration (in years) was $14.7(\mathrm{SD}=3.1)$ years. The majority of the participants consumed substances $1-2$ times per week $(21 \%)$ or daily $(18.5 \%)$.

The second group was composed of 162 Colombian healthy adults matched for age, sex and education with no history of consumption of illicit substances. These healthy adults were selected from the database of a study conducted to obtain normative data of the 10 most common neuropsychological measures in healthy individuals across 10 cities in Colombia (Arango-Lasprilla \& Rivera, 2015).

To be eligible for participation, individuals in both groups must have met the following requirements: (a) were between 18 and 45 years old, (b) were born and currently lived in Colombia, (c) spoke Spanish as their native language, (d) had completed at least one year of formal education and (e) were able to read and write at the time of evaluation. The inclusion criteria for individuals with CPUD were (a) diagnosis of cocaine use disorder, accompanied by a request for treatment for addiction to coca paste as the main substance and (b) ability and willingness to sign the informed consent form. The exclusion criteria for individuals with CPUD were: (a) a history of diagnosis of psychiatry conditions (schizophrenia, schizophreniform disorder, schizoaffective disorder, or delusional disorder), (b) intoxication or serious organic disease at the time of the interview, (c) history of neurological alterations not related to the consumption of psychoactive substances, (d) immediate family history of psychosis, (e) history of learning disabilities and 
developmental disorders or (f) concomitant use of marijuana. The exclusion criteria for the HC were: (a) history of neurological or psychiatric conditions, (b) daily consumption and/or use of an illicit substance, (c) history of chronic disease (e.g., diabetes mellitus), (d) regular use of pain-killers or other medications that may impact cognitive performance, (e) severe visual and/or hearing deficit or (f) history of learning disabilities and developmental disorders. Finally, all the participants in both groups were volunteers and did not receive financial compensation for participation. The characteristics of both groups (age, years of education, and gender) can be found in Table 1.

\section{Insert Table 1}

\section{2. Measures}

Learning and memory domains were assessed with the Hopkins Verbal Learning TestRevised (HVLT-R) (Brandt, 1991) and the Rey-Osterrieth Complex Figure (ROCF) (Arango-Lasprilla, Stevens, Morlett-Paredes, Ardila, \& Rivera, 2017; Rivera et al., 2015). Language was measured using the Verbal Fluency Test (VFT) (Olabarrieta-Landa et al., 2015; Olabarrieta-Landa, Torre, López-Mugartza, Bialystok, \& Arango-Lasprilla, 2017) and the Boston Naming Test (BNT) (Kaplan, Goodglass, \& Weintraub, 2005). Finally, executive functions were tested with the Modified Wisconsin Card Sorting Test (M-WCST) (Schretlen, 2010), the Stroop Color-Word Interference Test (Golden, 2007), the Trail Making Test (TMT) (Reitan, 1992) and the Symbol Digit Modalities Test (SDMT) (Smith, 2002). The specific cognitive domains measured with the different tests, along with the median and the minimum/maximum for each group, are displayed in Table 2. More details about the tests used can be found in the supplemental materials.

\subsection{Procedure}


The University of San Buenaventura (Bogotá, Colombia) Research and Ethics Committee of the School of Psychology approved this study. To find participants for the coca-paste consumer group, several centers that specialize in the treatment of individuals who use addictive substances from the city of Bogotá were contacted. Three centers agreed to take part after receiving the approval from their scientific management team. Subsequently, conferences were held at the three centers to explain the purpose of the study and the inclusion and exclusion criteria to properly inform potential participants. Those who agreed to participate were individually asked to review and sign the informed consent forms. Once these individuals agreed to participate, they were interviewed, and the neuropsychiatric questionnaires were administered by specialized personnel. Those subjects who met the inclusion/exclusion criteria completed a neuropsychological evaluation for an average of 1.5-2 hours. The neuropsychological evaluations were conducted by psychologists with a specialization in neuropsychology and with specific training in the administration of the neuropsychological tests.

Data collection started in March and finished in December 2017. The HC group was obtained from a larger study to generate normative data for Spanish-language neuropsychological tests for the Colombian population (Arango-Lasprilla \& Rivera, 2015; Guàrdia-Olmos, Rivera, Peró-Cebollero, \& Arango-Lasprilla, 2015). Purposive sampling was used, and recruitment materials were distributed through a range of organizations, such as universities, community businesses, churches, and services for older adults. The 168 healthy participants were selected from a database consisting of 1425 clinically healthy subjects (Guàrdia-Olmos et al., 2015) to match the CPUD group according to age, sex and years of education. 


\subsection{Data analysis}

The data were analysed using SPSS version 25. Descriptive statistics were obtained. The Kolmogorov-Smirnov and Levene's tests were applied to evaluate normal distribution and homoscedasticity. The Mann-Whitney U test was applied to verify that the samples did not differ in age and number of years in formal education, and the gender distribution was evaluated by the chi-squared test. In addition, different test scores were grouped into three domains using $\mathrm{Z}$ composite scores: learning and memory (HVLT-R and ROCF), language (VFT and BNT) and executive functions (M-WCST, Stroop, TMT and SDMT). Each Z composite score was created using Stouffer's Z method (Whitlock, 2005). Student's t-test analyses were used to compare groups according to these three domains. Since the sample size was large, Cohen's effect size $(d)$ was calculated to determine practically significant group differences in neuropsychological scores, with the cut-off point of 0.20 as small, 0.50 as medium, and 0.80 as large effect sizes (Cohen, 1992).

Finally, the effects of group and demographic variables on each neuropsychological domain were evaluated with a multiple linear regression analysis. The full regression model included as predictors: age, age ${ }^{2}$, years of education, education ${ }^{2}$, group, sex, and all twoway interactions between these variables. Age and years of education were centered (= calendar age in years - mean age in the sample; education in years - mean education in the sample) before computing the quadratic age and education levels to avoid multicollinearity (Kutner, Nachtsheim, Neter, \& Li, 2005). Squared terms of age and years of education were added in the full model to allow for quadratic effects between these independent variables and the domains (i.e., non-linear relations between age/education and the domains). Independent variables that were not statistically significant (using an alpha-level of 0.05/14 independent variables $\cong 0.003$ ) in the full multiple regression model (i.e., the model shown 
above that includes all independent variables and their two-way interactions) were removed in a stepwise hierarchical manner. In the model-building procedure, predictors were not removed as long as they were included in a higher order term in the model (Aiken, West, \& Reno, 1991).

\section{Results}

\subsection{Descriptive statistics}

The Kolmogorov-Smirnov statistic showed that the neuropsychological raw scores were not normally distributed (p-values $2.6 \times 10^{-56}$ [HVLT-R Recognition] to $4.1 \times 10^{-2}$ [Stroop Color]). Nine (i.e., Letter A, Letter S, ROCF Copy, M-WCST Categories) of the 15 neuropsychological scores showed heteroscedasticity according to the Levene's tests. For this reason, a U Mann-Whitney test comparison between groups was used. Descriptive analyses showed that the healthy sample did not differ from the consumer sample in terms of age $(\mathrm{U}=12298 ; p=0.328)$, gender $\left(\chi^{2}=3.345 ; p=0.067\right)$ or years of education $(\mathrm{U}=25501$; $p=0.131)($ see Table 1$)$.

\subsection{Neuropsychological comparison between groups}

A series of $U$ Mann-Whitney tests showed a significant difference between individuals with CPUD and HC in 13 of 15 neuropsychological scores (i.e., HVLT-R Total recall $[\mathrm{U}=6623.5, p<0.001, d=0.85]$, ROCF Copy $[\mathrm{U}=6351.0, p<0.001, d=0.82])$; the HC group performed better than CPUD group. There were no significant differences in the TMT-A test $(\mathrm{U}=12317.0 ; p=0.340, d=0.12)$ or the fruits category $(\mathrm{U}=11937.0 ; p=0.158$, $d=0.12)$ of the verbal fluency test (see Table 2$)$. Effect sizes ranged from small $(d \geq 0.3)$ to medium $(d \geq 0.5)$ in the confirmed difference between groups. 


\section{Insert Table 2}

Additionally, normative data for the Colombian population (Arango-Lasprilla \& Rivera, 2015; Olabarrieta-Landa et al., 2019; Rivera et al., 2019) were used to convert raw scores to adjusted Z-scores. The Z-scores were grouped in the cognitive domain using Stouffer's Z method. Then, analyses were run to determine whether significant differences were found by each domain. The results presented in Table 3 show significant differences between the groups in learning and memory $(\mathrm{t}=11.090 ; p<0.001)$, language $(\mathrm{t}=4.082$; $p<0.001)$ and executive functions $(\mathrm{t}=5.359 ; p<0.001)$; individuals with CPUD scored lower than the HC.

\section{Insert Table 3 here}

\subsection{Regression models}

The final model showed significant interactions between Group and Education in the Learning and Memory and the Language domains (Table 4). Thus, the HC had higher scores according to additional years of education, while the CPUD scores increased according to years of education but with a substantially lower slope (see Figures 1A, 1B). In contrast, specific to the Executive Function domain, a significant main effect for group, age and years of education was found; in the HC group, younger participants and those with

greater years of education had higher scores (see Figure 1C). The amount of variance explained by these predictors (adjusted $R^{2}$ ) ranged from 18\% (Language) to $34.7 \%$ (Learning and Memory).

Insert Table 4 and Figure 1 


\section{Discussion}

The purposes of this study were to characterize the neuropsychological profile of a group of individuals with CPUD compared to a group of $\mathrm{HC}$ and to determine the relationship between cognitive performance and sociodemographic characteristics of these groups. The results showed that the CPUD group scored significantly lower than the HC group on tests that measure the domains of learning and memory (both visual and verbal), language and executive functions. These results were consistent with previous studies that have determined that individuals with CPUD disorder may have brain damage, particularly in the prefrontal-subcortical areas, limbic structures and association cortices (Ferrando et al., 2009; Lopez-Hill et al., 2011; Meikle et al., 2009; Prieto et al., 2015; Schwarzkopf et al., 2018). This damage matches the neuropsychological deficits found in individuals with CPUD, especially in memory and executive functions.

Thereby, if we compare the cognitive performance of individuals with CPUD to that of cocaine hydrochloride consumers (administered differently, such as snorted, or with a different composition, such as cocaine hydrochloride or crack), we discover very similar neuropsychological deficits between these groups, particularly in terms of learning, memory, language and executive functions. Delgado Vivas (2011) conducted a study in which they compared the neurological impairment of individuals with CPUD with that of cocaine hydrochloride consumers. These authors found a lower brain flow in the prefrontalsubcortical areas, limbic structures and association cortices in individuals with CPUD than those of cocaine hydrochloride consumption. This was observed specifically in the anterior cingulate and the mesial, dorsolateral and ventromedial regions of the prefrontal cortex, which are associated with impulsivity problems, uninhibited and antisocial behaviours and incorrect emotional processing. These differences may be due to the higher speed of action 
of the brain on coca paste than cocaine hydrochloride which may indicate a different cognitive pattern (Delgado Vivas, 2011).

Recently, several systematic reviews of the cognitive performance of individuals with cocaine use have been published (Frazer, Richards, \& Keith, 2018; Potvin, Stavro, Rizkallah, \& Pelletier, 2014; Spronk et al., 2013). Spronk et al. (2013) published a metaanalysis with the goal of analysing the short- and long-term cognitive deficits of cocaine consumers. These authors concluded that long-term cognitive deficits are common in the areas of attention, memory and executive performance, specifically in decision-making, flexibility and inhibition. In another study, Potvin et al. (2014) found that cocaine use is related to cognitive deficits in attention, impulsivity, learning, memory and working memory. Finally, Frazer et al. (2018) analysed the effects of cocaine hydrochloride at the brain level and its relationship with cognitive impairment. These authors found that chronic cocaine consumption is not associated with extensive cognitive impairment. However, compared to healthy controls, individuals who use cocaine present some differences in brain structures, blood-oxygen-level dependent signals and brain metabolism. In conclusion, all these studies seem to support the presence of cognitive impairments in this population.

To the best of our knowledge, this is the only study in the literature that has investigated the effects on neuropsychological functioning of consuming coca paste. Other studies have been carried out in animals. Meikle et al. (2013) analysed the suppressive effect on the aggressiveness of rats long after they had consumed coca paste. The reduction in their aggressiveness may be due to the increase in the cortical levels of serotonin (5-HT) which were caused by the consumption of coca paste. According to Lopez-Hill et al. (2011), the components responsible for the stimulating effect of coca paste are cocaine and 
caffeine (as an adulterant added to coca paste). These results coincide with those from another study which showed that caffeine increases the sensitivity of rats that have consumed coca paste (Prieto et al., 2015). Schwarzkopf et al. (2018) also showed the importance of caffeine as an adulterant of coca paste, with more problems in the sleep cycles of rats that had consumed coca paste and caffeine than of rats that had only consumed coca paste (which has similar effects to cocaine). These studies have generated new hypotheses that must be investigated; for example, analysing the differential effect that the adulterant of caffeine may have on the chemical composition of coca paste and its effect on neuropsychological functioning. Coca paste is characterized by the various quantities of adulterants and impurities that it contains which may affect neuropsychological functioning differently.

With respect to determining the relationship between cognitive performance of individuals with CPUD and sociodemographic characteristics, such as age, educational level and group (CPUD versus HC), the results indicated that coca paste consumption was related to cognitive impairment in the three neuropsychological domains measured (learning and memory, language and executive function), and an interaction between group and years of education was only observed in the cognitive domains of learning and memory and language. These results are consistent with previous studies, which found that the most common neuroprotector variables associated with cognitive performance are education, occupational attainment, leisure and social activities and premorbid IQ (Barulli \& Stern, 2013; Cabeza et al., 2018; Harrison, Sajjad, Bramer, Ikram, Tiemeier, \& Stephan, 2015; Kesler, Adams, Blasey, \& Bigler, 2003). However, our results suggested that although years of education is a protective factor for cognitive impairment, the expected results did not appear in the CPUD group in the domains of memory and learning and language; 
however, the expected results were observed in the executive functions. Despite the effect that education may have on the CPUD group, its protection at the level of cognitive impairment is different depending on the cognitive area, and in some cases is not enough. Educational level is one of the measures of cognitive functional reserve, together with premorbid IQ and premorbid brain size; a low educational level increases the risk of cognitive deficit (Fein, \& Di Sclafani, 2004). In a recent study, the authors showed the importance of taking into account certain factors in the cognitive recovery of patients with substance addiction, including education level, education level of parents, work occupation, musical training or language learning (all this is integrated within the concept of cognitive reserve; Fernández-Del Olmo et al., 2019).

One of the main implications of this study is that cognitive deficits are common in individuals with CPUD, which could imply that more research is necessary to implement neuropsychological intervention as part of rehabilitation programs for these individuals. According to recent studies, the most suitable treatment for individuals who use drugs is cognitive rehabilitation (Pedrero-Pérez et al., 2011; Verdejo-Garcia, 2016; Verdejo-García et., 2019), especially for the areas of executive function, memory and learning. According to Verdejo-García, Garcia-Fernandez \& Dom (2019), deficits in executive functions (and especially in decision-making) are adequate predictors to prevent relapses, so intervention programs should especially focus on this cognitive domain. There are two main methods to improve cognitive deficits in individuals who use substances: computerized training through exercises with specific software such as cognitive bias modification (CBM) and cognitive rehabilitation focused on improving the functioning in real life tasks. Other useful interventions are Goal Management Training (GMT), which helps to improve decisionmaking (Alfonso, Caracuel, Delgado-Pastor \& Verdejo-García, 2011; Valls-Serrano, 
Caracuel, \& Verdejo-Garcia, 2016) and working memory training (WM training). Likewise, there appears to be some evidence for the advantages of using a combination of these three interventions to improve efficacy (CBM, GMT and WM training; Verdejo, García-Fernandez et al., 2019). All these interventions may be adequate for patients who consume coca paste, although more studies would be necessary to measure their effectiveness.

The results of this study should be interpreted in light of the following limitations. First, this research was a cross-sectional study, and future studies should be undertaken to investigate the long-term trajectories of the cognitive problems that were found here. Additionally, the neuropsychological battery of this study included only tests of three cognitive domains, and we cannot generalize these cognitive problems to other areas that have not been studied; for example, information processing speed, intelligence and perception. Another limitation of our study is the duration and intensity of coca paste consumption as well as the comorbidity of the other substances in which were consumed and not measured. It is not possible to determine how these variables may have been related to the cognitive performance of these groups. In this investigation, we did not include measures of motivation or task engagement as part of the neuropsychological protocol. Future studies should include validity tests in evaluation protocols. Finally, a complete evaluation of cognitive reserve was not carried out. It would be advantageous to replicate the data by applying a complete questionnaire to measure cognitive reserve. Despite these limitations, to the best of our knowledge, there have been no studies that have compared the cognitive performance of individuals with coca paste use disorders to that of healthy individuals, taking into account sociodemographic characteristics. 


\section{Conclusions}

In conclusion, this study suggests that neuropsychological deficits exist related to CPUD in the areas of learning and memory, executive functions and to a lesser extent language. The data also revealed how, in the case of individuals with CPUD, educational level would not be a protective factor to prevent cognitive impairments in memory and learning and language.

The results of this study have some implications for clinical practice and research. It may be necessary to broaden the study of cognitive effects of coca paste consumption and the differences with respect to the consumption of other substances. As in other studies, the results of this study show differential effects with respect to the neuroprotective factors of this substance (Fernández-Del Olmo et al., 2019). Educational level may differentially protect against cognitive impairment in individuals who consume substances, and it may also affect some cognitive domains more than others (for example, perhaps protecting against the deterioration of executive functions more than language and memory). Future studies should develop and implement cognitive rehabilitation programs for coca pastedependent individuals to improve cognitive functions in the areas of memory, language and executive functions.

\section{Role of funding sources}

This work did not have any type of funding or grant-awarding bodies.

\section{Authors' contribution}

EVM, SSR, DR, FGS and JCAL designed the study. MRAB and JAPP participated in the assessment protocols and administration. DR and JCAL conducted statistical analyses. 
EVM, SSR, DR, FGS and JCAL contributed to the interpretation of the data. EVM, SSR,

DR and JCAL developed a first draft. All the authors contributed to improve the draft and approved the final version.

\section{Conflict of interest}

The authors declare that they have no known competing financial interests or personal relationships that could have appeared to influence the work reported in this manuscript.

\section{References}

Aiken, L. S., West, S. G., \& Reno, R. R. (1991). Multiple regression: Testing and interpreting interactions. California: Sage.

Alfonso, J. P., Caracuel, A., Delgado-Pastor, L. C., \& Verdejo-García, A. (2011). Combined goal management training and mindfulness meditation improve executive functions and decision-making performance in abstinent polysubstance abusers. Drug and alcohol dependence, $117(1), 78-81$.

Alonso-Matías, L., Reyes-Zamorano, E., \& González-Olvera, J., (2019). Funcionamiento cognitivo en sujetos con trastorno de dependencia a cocaína y crack durante la abstinencia temprana [Cognitive functions of subjects with cocaine and crack dependency disorder during early abstinence]. Revista de Neurología, 7, 271-280. http://dx.doi.org/10.33588/rn.6807.2018119.

Arango-Lasprilla, J. C. \& Rivera, D. (2015). Neuropsicología en Colombia: Datos normativos, estado actual y retos a futuro [Neuropsychology in Colombia: Normative data, current state and future challenges]. Manizales, Colombia: Editorial Universidad Autónoma de Manizales.

Arango-Lasprilla, J. C., Rivera, D., Aguayo, A., Rodríguez, W., Garza, M. T., Saracho, C. P., .. \& Longoni, M. (2015a). Trail making test: Normative data for the Latin American Spanish speaking adult population. NeuroRehabilitation, 37(4), 639-661. http://dx.doi.org/10.3233/NRE-151284.

Arango-Lasprilla, J. C., Rivera, D., Rodríguez, G., Garza, M. T., Galarza-Del-Angel, J., Rodriguez, W., ... \& Longoni, M. (2015b). Symbol digit modalities test: normative data for the Latin American Spanish speaking adult population. NeuroRehabilitation, 37(4), 625-638. http://dx.doi.org/10.3233/NRE-151282.

Arango-Lasprilla, J. C., Stevens, L., Morlett Paredes, A., Ardila, A., \& Rivera, D. (2017). Profession of neuropsychology in Latin America. Applied Neuropsychology: Adult, 24(4), 318-330. http://dx.doi.org/10.1080/23279095.2016.1185423.

Ashok AH, Mizuno Y, Volkow ND, Howes OD. (2017) Association of Stimulant Use With Dopaminergic Alterations in Users of Cocaine, Amphetamine, or 
Methamphetamine: A Systematic Review and Meta-analysis. JAMA Psychiatry, 74(5), 511-519. http://dx.doi.org/10.1001/jamapsychiatry.2017.0135.

Barulli, D., \& Stern, Y. (2013). Efficiency, capacity, compensation, maintenance, plasticity: emerging concepts in cognitive reserve. Trends in cognitive sciences, 17(10), 502-509. http://dx.doi.org/10.1016/j.tics.2013.08.012.

Brandt, J., (1991). The Hopkins Verbal Learning Test: Development of a new memory test with six equivalent forms. Clinical Neuropsychology, 5, 125-142. http://dx.doi.org/10.1080/13854049108403297.

Cabeza, R., Albert, M., Belleville, S., Craik, F. I., Duarte, A., Grady, C. L., ... \& Rugg, M. D. (2018). Maintenance, reserve and compensation: the cognitive neuroscience of healthy ageing. Nature Reviews Neuroscience, 1. http://dx.doi.org/10.1038/s41583018-0068-2.

Castaño, P. (2000). Cocaínas fumables en Latinoamérica [Smokeable Cocaines in Latin America]. Adicciones, 12, 541-550. http://dx.doi.org/10.20882/adicciones.664.

Cohen, J. (1992). A power primer. Psychological bulletin, 112(1), 155.

Czermainski, F., Willhelm, A., Santos, A., Pachado, P., \& De Almeida, M. (2017). Assessment of inhibitory control in crack and/or cocaine users: a systematic review. Trends Psychiatry Psychotherapy, 39, 216-25. http://dx.doi.org/ 10.1590/2237-60892016-0043.

Delgado Vivas, H. I. (2011). Alteraciones del flujo sanguíneo cerebral en consumidores activos de pasta base y clorhidrato de cocaina (Tesis de Grado) [Alterations of cerebral blood flow in active consumers of base paste and cocaine hydrochloride. Thesis]. Universidad de la República de Uruguay, Facultad de Ciencias.

Fein, G., \& Di Sclafani, V. (2004). Cerebral reserve capacity: implications for alcohol and drug abuse. Alcohol, 32(1), 63-67.

Fernández-Del Olmo, A., Cruz-Cortés, M., Conde, C., Ontanilla, E., Rosa-Muela, C., Martos, C., Cáceres, D., \& Ruiz-Sánchez de León, J.M. (2019). The role of the cognitive reserve in the cognitive recovery of patients who have suffered a severe addiction to substances. Revista de Neurología, 69 (08), 323-331. http://dx.doi.org/

Fernández-Serrano, M.J., Pérez-García, M. \& Verdejo-García, A. (2011). What are the specific vs. generalized effects of drug of abuse on neuropsychological performance? Neuroscience and Biobehavioral Reviews 35, 377-406. http://dx.doi.org/10.1016/j.neubiorev.2010.04.008 .

Fernández-Serrano, M.J., Perales, J.C., Moreno-López, L., Pérez-García, M. \& VerdejoGarcía, A. (2012). Neuropsychological profiling of impulsivity and compulsivity in

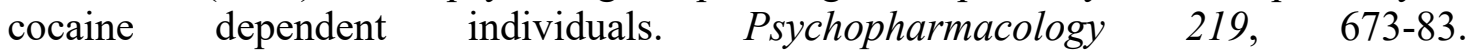
http://dx.doi.org/10.1007/s00213-011-2485-z .

Ferrando, R., Bocchino, S., Barrachina, A., Ferro, A., Rodríguez, J., Silveira, A., Ventura, R., Gioia, A. López, A., Langhain, M. Cardoso, A., Zurmendi, P., Triaca, J. \& Lago, G. (2009). Alteraciones de la perfusión cerebral en consumidores activos de pasta base de cocaína [Alterations of cerebral perfusion in active consumers of cocaine base paste]. Revista de psiquiatría del Uruguay, 73, 51-62.

Frazer, K. M., Richards, Q., \& Keith, D. R. (2018). The long-term effects of cocaine use on cognitive functioning: A systematic critical review. Behavioural Brain Research, 348, 241-262. http://dx.doi.org/ 10.1016/j.bbr.2018.04.005.

Fukushima, A.R., Carvalho, V.M., Carvalho, D.G., Diaz, E., Bustillos, J.O., Spinosa, Hde, S., \& Chasin, A.A. (2014). Purity and adulterant analysis of crack seizures in Brazil. 
Forensic Science International, 243, 95-98. http://dx.doi.org/ 10.1016/j.forsciint.2014.05.002.

Galvalisi, M., Prieto, J.P., Martinez, M., Abin-Carriquiry, J.A., \& Scorza, C. (2015). Smoked cocaine: chemical analysis of seized samples and the role of caffeine in its central actions. IBRO 9th World Congress, Rio de Janeiro.

Golden, C. J. (2007). Manual Stroop, Test de Colores y Palabras (5 Edición) [Stroop Manual, Color and Word Test (5th Edition)]. Madrid: Tea Ediciones, S.A.

Guàrdia-Olmos, J., Peró-Cebollero, M., Rivera, D., \& Arango-Lasprilla, J. C. (2015). Methodology for the development of normative data for ten Spanish-language neuropsychological tests in eleven Latin American countries. NeuroRehabilitation, 37(4), 493-499. http://dx.doi.org/ 10.3233/NRE-151277.

Harrison, S. L., Sajjad, A., Bramer, W. M., Ikram, M. A., Tiemeier, H., \& Stephan, B. C. (2015). Exploring strategies to operationalize cognitive reserve: A systematic review of reviews. Journal of clinical and experimental neuropsychology, 37(3), 253-264. http://dx.doi.org/ 10.1080/13803395.2014.1002759.

Jovanovski, D. \& Zakzanis, K. (2005). Neurocognitive Deficits in Cocaine Users: A Quantitative Review of the Evidence. Journal of clinical and experimental neuropsychology, 27, 189-204. http://dx.doi.org/ 10.1080/13803390490515694.

Kaplan, E., Goodglass, H., \& Weintraub, S. (2005). Test de Vocabulario de Boston (2 ${ }^{\circ}$ ed.) [Boston Vocabulary Test (2nd ed.)]. Madrid: Editorial Médica Paramericana, S.A.

Kemmis, L., Hall, J., Kingston, R. \& Morgan, M. (2007). Impaired fear recognition in regular recreational cocaine users. Psychopharmacology, 194,151-9. http://dx.doi.org/ 10.1007/s00213-007-0829-5.

Kutner, M. H., Nachtsheim, C. J., Neter, J., \& Li, W. (2005). Applied linear statistical models (Vol. 5). New York: McGraw-Hill Irwin.

Lizasoain, I., Moro, M.A., \& Lorenzo, P. (2002). Cocaína: aspectos farmacológicos [Cocaine: pharmacological aspects]. Adicciones, 14, 57-64. http://dx.doi.org/

Lopez-Hill, X., Prieto, J.P., Meikle, M.N., Urbanavicius, J., Abin-Carriquiry, J.A., Prunell, G., Umpierrez, E., \& Scorza, M.C. (2011). Coca-paste seized samples characterization: chemical analysis, stimulating effect in rats and relevance of caffeine as a major adulterant. Behavioural Brain Research, 221, 134-141. http://dx.doi.org/ 10.1016/j.bbr.2011.03.005.

Meikle, M., Urbanavicius, J., Prunell, G., Umpiérrez, E., Abín-Carriquiry, A. \& Scorza, M. (2009). Primer estudio pre-clínico de la acción de pasta base de cocaína en el sistema nervioso central [First pre-clinical study of the action of cocaine base paste in the central nervous system]. Revista de psiquiatría del Uruguay, 73, 25-36.

Meikle, M.N., Prieto, J.P., Urbanavicius, J., Lopez, X., Abin-Carriquiry, J.A., Prunell, G., \& Scorza, M.C. (2013). Anti-aggressive effect elicited by coca-paste in isolation-induced aggression of male rats: influence of accumbal dopamine and cortical serotonin. Pharmacology, Biochemistry and Behavior, 110, 216-223. http://dx.doi.org/ 10.1016/j.pbb.2013.07.010.

Observatorio de Drogas de Colombia (ODC) (2017). Reporte de Drogas de Colombia [Colombia Drug Report]. Bogotá: Ministerio de Justicia y del Derecho.

Olabarrieta-Landa, L., Rivera, D., Galarza-Del-Angel, J., Garza, M. T., Saracho, C. P., Rodríguez, W., ... \& Martínez, C. (2015). Verbal fluency tests: Normative data for the Latin American Spanish speaking adult population. NeuroRehabilitation, 37(4), 515561. http://dx.doi.org/10.3233/NRE-151279. 
Olabarrieta-Landa, L., Torre, E. L., López-Mugartza, J. C., Bialystok, E., \& ArangoLasprilla, J. C. (2017). Verbal fluency tests: Developing a new model of administration and scoring for Spanish language. NeuroRehabilitation, 41(2), 539-565. http://dx.doi.org/10.3233/NRE-162102.

Olabarrieta-Landa, L., Ramos-Usuga, D., Rivera, D., Leal, G., Bailey, K.C., CalderoChaguala, A., ... \& Arango-Lasprilla, J.C. (2019) Prevalence of Low Scores on Language Tests as a Potential Factor in Misdiagnosis of Cognitive Impairment in a Spanish-Speaking Adult Population. Applied Neuropsychology: Adult. doi: 10.1080/23279095.2019.1704409.

Orsini CA, Colon-Perez LM, Heshmati SC, Setlow B, Febo M. (2018) Functional Connectivity of Chronic Cocaine Use Reveals Progressive Neuroadaptations in Neocortical, Striatal, and Limbic Networks. eNeuro., 5 (4), ENEURO.0081-18.2018. http://dx.doi.org/10.3233/NRE-162102

Parkin Daniels, J. (2015). Bogotá tackles basuco addiction. The Lancet, 12-18, 1027-1028. https://doi.org/10.1016/S0140-6736(15)00189-0

Pascale, A., Hynes, M., Cumsille, F., \& Bares, C. (2014). Consumo de pasta base de cocaína en América del Sur: revisión de los aspectos epidemiológicos y médicotoxicológicos [Cocaine base paste consumption in South America: review of epidemiological and medical-toxicological aspects]. Washington DC: Organización de los Estados Americanos.

Pedrero-Pérez, E. J., Rojo-Mota, G., Ruiz-Sánchez de León, J. M., Fernández-Méndez, L. M., Morales-Alonso, S., \& Prieto-Hidalgo, A. (2014). Reserva cognitiva en adictos a sustancias en tratamiento: relación con el rendimiento cognitivo y las actividades cotidianas. Revista de Neurología, 59(11), 481-489. http://dx.doi.org/10.33588/rn.5911.2014435.

Pedrero-Pérez, E. J., Rojo-Mota, G., Ruiz-Sánchez de León, J. M., Llanero-Luque, M., \& Puerta-García, C. (2011). Rehabilitación cognitiva en el tratamiento de las adicciones [Cognitive remediation in addictions treatment]. Revista de Neurología, 52(3), 163172.

Pérez, J. (2003). Clínica de la adicción a pasta base de cocaína [Cocaine Base Addiction Clinic]. Revista Chilena de Neuropsiquatría, 41, 55-63. http://dx.doi.org/ 10.4067/S0717-92272003000100007.

Potvin, S., Stavro, K., Rizkallah, É., \& Pelletier, J. (2014). Cocaine and cognition: a systematic quantitative review. Journal of Addiction Medicine, 8, 368-376. http://dx.doi.org/ 10.1097/ADM.0000000000000066.

Prieto, J. P., Galvalisi, M., López-Hill, X., Meikle, M. N., Abin-Carriquiry, J. A., \& Scorza, C. (2015). Caffeine enhances and accelerates the expression of sensitization induced by coca paste indicating its relevance as a main adulterant. The American Journal on Addictions, 24, 475-481. http://dx.doi.org/10.1111/ajad.12245.

Prieto, J.P., Lopez-Hill, X., Meikle, M.N., Abin-Carriquiry, J.A., \& Scorza, C. (2012). Relevancia del adulterante activo cafeina en la acción estimulante de la pasta base de cocaína. [Relevance of active coffee adulterant in the stimulating action of coca-paste]. Revista de Psiquiatría de Uruguay, 76, 35-48.

Reitan, R.M. (1992). Trail Making Test. Manual for administration and scoring. Tucson, AZ: Reitan Neuropsychology Laboratory.

Rey, A. (2009). REY: Test de copia y de reproducción de memoria de figuras geométricas 
complejas [Memory copy and replay test of complex geometric figure]. Madrid: TEA ediciones.

Rivera, D., Perrin, P. B., Morlett-Paredes, A., Galarza-del-Angel, J., Martinez, C., Garza, M. T., ... \& Aliaga, A. (2015). Rey-Osterrieth Complex Figure-copy and immediate recall: Normative data for the Latin American Spanish speaking adult population. NeuroRehabilitation, 37(4), 677-698. http://dx.doi.org/ 10.3233/NRE-151285.

Rivera, D., Olabarrieta-Landa, L., Brooks, B., Ertl, M.M., Benito-Sánchez, I., Quijano, M.C., Rodriguez-Irizarry, W., Aguayo-Arelis, A., Rodríguez-Agudelo, Y. \& ArangoLasprilla, J.C. (2019). Multivariate Base Rates of Low Scores on Tests of Learning and Memory Among Latino Adult Populations. Journal of the International Neuropsychological Society, 25(8), 834-844. doi: 10.1017/S135561771900050X.

Sabogal-Carmona, J. \& Urrego-Novoa, J. (2012). Composición química de muestras de bazuco incautado en Colombia primer semestre de 2010 [Chemical composition of samples of bazuco seized in Colombia first half of 2010]. Revista de Salud Pública, $14,1014-1025$.

Schretlen, D. (2010). Modified Wisconsin Card Sorting Test: MWCST. Professional Manual. New York: PAR.

Schwarzkopf, N., Lagos, P., Falconi, A., Scorza, C. \& Torterolo, P. (2018). Caffeine as an adulterant of coca paste seized samples: preclinical study on the rat sleep-wake-cycle. $\begin{array}{lll}\text { Behavioural Pharmacology, 29, 519-529. } & \text { P. }\end{array}$ http://dx.doi.org/10.1097/FBP.0000000000000417.

Smith, A. (2002). Manual de test de símbolos y dígitos-SDMT. Publicaciones de psicología aplicada [Symbols and digits test manual SDMT. Publications of applied psychology]. Madrid: TEA ediciones.

Spronk, D. B., Van Wel, J. H., Ramaekers, J. G. \& Verkes, R. J. (2013). Characterizing the cognitive effects of cocaine: a comprehensive review. Neuroscience \& Biobehavioral Reviews, 37, 1838-1859. http://dx.doi.org/ 10.1016/j.neubiorev.2013.07.003.

Stern, Y. (2017). An approach to studying the neural correlates of reserve. Brain Imaging and Behavior, 11, 410-6. http://dx.doi.org/10.1007/s11682-016-9566-x.

Stern, Y. (2009). Cognitive reserve. Neuropsychologia, 47, 2015-28. http://dx.doi.org/ 10.1016/j.neuropsychologia.2009.03.004.

Stern, Y. (2002). What is cognitive reserve? Theory and research application of the reserve concept. Journal of the International Neuropsychological Society, 8, 448-460.

United Nations Office on Drugs and Crime (UNODC), 2019 . World Drug Report. Avaible at: https://wdr.unodc.org/wdr2019/index.html.

Valls-Serrano, C., Caracuel, A., \& Verdejo-Garcia, A. (2016). Goal Management Training and Mindfulness Meditation improve executive functions and transfer to ecological tasks of daily life in polysubstance users enrolled in therapeutic community treatment. Drug and Alcohol Dependence, 165, 9-14.

Vázquez-Justo, E., Blanco, A. P., Vergara-Moragues, E., Gestoso, C. G., \& Pérez-García, M. (2014). Cognitive reserve during neuropsychological performance in HIV intravenous drug users. Applied Neuropsychology: Adult, 21(4), 288-296. http://dx.doi.org/10.1080/23279095.2013.813852.

Verdejo-Garcia, A. (2016). Cognitive training for substance use disorders: Neuroscientific mechanisms. Neuroscience \& Biobehavioral Reviews, 68, 270-281.

Verdejo-García, A., Betanzos-Espinosa, P., Lozano, O.M., Vergara Moragues, E., GonzálezSaiz, F., Fernández-Calderón, F., Bilbao-Acedos, I., \& Pérez-García, M. (2012). Self- 
regulation and treatment retention in cocaine dependent individuals: A longitudinal study. Drug and Alcohol Dependence, 122, 142-8. http://dx.doi.org/10.1016/j.drugalcdep.2011.09.025.

Verdejo-Garcia, A., Garcia-Fernandez, G., \& Dom, G. (2019). Cognition and addiction. Dialogues in clinical neuroscience, 21(3), 281.

Verdejo-García, A., Lorenzetti, V., Manning, V., Piercy, H., Bruno, R., Hester, R., ... \& Bowden-Jones, H. (2019). A Roadmap for Integrating Neuroscience into Addiction Treatment: A Consensus of the Neuroscience Interest Group of the International Society of Addiction Medicine. Frontiers in Psychiatry, 10, 877.

Verdejo-García, A. \& Rubenis, A.J. (2020). Cognitive déficits in people with stimulant use disorders. In Verdejo-García, A. Cognition and Addiction: A researcher's guide from mechanisms towards interventions. 155-163. https://doi.org/10.1016/B978-0-12$\underline{815298-0.00011-3}$

Vergara-Moragues, E., Verdejo-García, A., Lozano, O.M., Santiago-Ramajo, S. GonzálezSaiz, F., Betanzos Espinosa, P. \& Pérez García, M. (2017). Association between executive function and outcome measure of treatment in therapeutic community among cocaine dependent individuals. Journal of Substance Abuse Treatment, 78, 45-55. http://dx.doi.org/10.1016/j.jsat.2017.04.014.

Vonmoos, M., Hulka, L. M., Preller, K. H., Minder, F., Baumgartner, M. R., \& Quednow, B. B. (2014). Cognitive impairment in cocaine users is drug-induced but partially reversible: Evidence from a longitudinal study. Neuropsychopharmacology, 39, 22002210. https://doi.org/10.1038/npp.2014.71.

Whitlock, M. C. (2005). Combining probability from independent tests: the weighted Z-method is superior to Fisher's approach. Journal of Evolutionary Biology, 18(5), 1368-1373. https://doi.org/10.1111/j.1420-9101.2005.00917.x. 
Table 1. Sample distribution by age, years of education and gender.

\begin{tabular}{|c|c|c|c|c|c|}
\hline Variable & Group & Median & Min - Max & $\mathrm{U}$ & $p$ value \\
\hline \multirow[b]{2}{*}{ Age } & Healthy & 31 & $18-47$ & \multirow[b]{2}{*}{12298} & \multirow{2}{*}{.328} \\
\hline & CPUD & 28 & $18-47$ & & \\
\hline \multirow{3}{*}{ Education } & Healthy & 11 & $5-13$ & \multirow{2}{*}{25501} & \multirow{2}{*}{.131} \\
\hline & CPUD & 11 & $5-13$ & & \\
\hline & & & & $\chi^{2}$ & $p$ value \\
\hline \multirow{2}{*}{ Gender } & Healthy & Female $70(43.2 \%)$ & Male $92(56.8 \%)$ & \multirow{2}{*}{3.345} & \multirow{2}{*}{.067} \\
\hline & CPUD & Female $54(33.3 \%)$ & Male $108(63.7 \%)$ & & \\
\hline
\end{tabular}

CPUD: Individuals with coca paste use disorder. 
Table 2. Comparisons between groups by neuropsychological test score.

\begin{tabular}{|c|c|c|c|c|c|c|}
\hline & Groups & Median & Min-Max & $U$ & $\begin{array}{c}\text { Sig. } \\
\text { (bilateral) }\end{array}$ & $\begin{array}{l}\text { Effect } \\
\text { size }(d)\end{array}$ \\
\hline \multirow{2}{*}{$\begin{array}{l}\text { HVLT-R Total } \\
\text { recall }\end{array}$} & Healthy & 21 & $8-32$ & \multirow{2}{*}{6623.5} & \multirow{2}{*}{$<.001$} & \multirow{2}{*}{0.85} \\
\hline & CPUD & 16 & $7-28$ & & & \\
\hline \multirow{2}{*}{$\begin{array}{c}\text { HVLT-R } \\
\text { Delayed recall }\end{array}$} & Healthy & 7 & $0-12$ & \multirow{2}{*}{7199.0} & \multirow{2}{*}{$<.001$} & \multirow{2}{*}{0.77} \\
\hline & CPUD & 5 & $1-11$ & & & \\
\hline \multirow{2}{*}{$\begin{array}{c}\text { HVLT-R } \\
\text { Recognition }\end{array}$} & Healthy & 11.5 & $8-12$ & \multirow{2}{*}{8537.5} & \multirow{2}{*}{$<.001$} & \multirow{2}{*}{0.65} \\
\hline & CPUD & 11 & $0-12$ & & & \\
\hline \multirow{2}{*}{ ROCF Copy } & Healthy & 34 & $9-36$ & \multirow{2}{*}{6351.0} & \multirow{2}{*}{$<.001$} & \multirow{2}{*}{0.82} \\
\hline & CPUD & 28 & $11-36$ & & & \\
\hline \multirow{2}{*}{ ROCF Recall } & Healthy & 21 & $3-35$ & \multirow{2}{*}{9317.0} & \multirow{2}{*}{$<.001$} & \multirow{2}{*}{0.48} \\
\hline & CPUD & 16 & $2.5-34$ & & & \\
\hline \multirow{2}{*}{ VFT Letter M } & Healthy & 12 & $1-25$ & \multirow{2}{*}{9465.5} & \multirow{2}{*}{$<.001$} & \multirow{2}{*}{0.52} \\
\hline & CPUD & 11 & $3-20$ & & & \\
\hline \multirow{2}{*}{ VFT Letter A } & Healthy & 11 & $4-25$ & \multirow{2}{*}{8722.5} & \multirow{2}{*}{$<.001$} & 057 \\
\hline & CPUD & 9 & $2-20$ & & & 0.51 \\
\hline VFT I etter S & Healthy & 10.5 & $2-24$ & 75105 & $<001$ & 073 \\
\hline VF I Letter S & CPUD & 8 & $3-20$ & 1510.5 & $<.001$ & 0.13 \\
\hline VET Animals & Healthy & 18 & $6-31$ & 105310 & 003 & 037 \\
\hline VF I Animais & CPUD & 16 & $7-25$ & 10531.0 & .003 & 0.31 \\
\hline VFT Fruits & Healthy & 14 & $1-22$ & 110370 & 158 & 013 \\
\hline VF & CPUD & 14 & $7-23$ & 11951.0 & .150 & 0.15 \\
\hline BNT & Healthy & 45 & $23-58$ & 87545 & $<001$ & 060 \\
\hline DIN 1 & CPUD & 49 & $32-59$ & & .001 & 0.00 \\
\hline SDMT & Healthy & 39 & $11-79$ & 82515 & $<001$ & 060 \\
\hline SDIMI & CPUD & 28.5 & $13-79$ & $8251 . J$ & $<.001$ & 0.00 \\
\hline Stron words & Healthy & 97 & $44-145$ & 104700 & $<001$ & 030 \\
\hline Stioup words & CPUD & 89 & $36-129$ & $104 / 0.0$ & -.001 & 0.53 \\
\hline Stroon colore & Healthy & 68.5 & $27-146$ & 108355 & 007 & 035 \\
\hline Stroop colois & CPUD & 63 & $21-93$ & נ & .001 & 0.53 \\
\hline Stroop Word- & Healthy & 42.5 & $13-88$ & 81455 & $<001$ & 069 \\
\hline Color & CPUD & 34 & $9-61$ & 0143.5 & -.001 & 0.07 \\
\hline TMT A & Healthy & 54 & $17-100$ & 123170 & 340 & 012 \\
\hline IIVI A & CPUD & 51.5 & $13-180$ & 12517.0 & .340 & 0.12 \\
\hline TMT B & Healthy & 100.5 & $41-300$ & 104410 & 001 & 027 \\
\hline & CPUD & 84.5 & $33-300$ & & & 0.21 \\
\hline M-WCST & Healthy & 5 & $0-6$ & 71300 & $<001$ & 081 \\
\hline Categories & CPUD & 3 & $1-6$ & 1150.0 & .001 & 0.01 \\
\hline
\end{tabular}

HVLT-R: Hopkins Verbal Learning Test-Revised; ROCF: Rey-Osterrieth Complex Figure; VFT: Verbal fluency tests; BNT: Boston Naming Test; SDMT: Symbol Digit Modalities Test; TMT: Trail Making Test; MWCST: Modified Wisconsin Card Sorting Test; CPUD: individuals with coca paste use disorder. 
Table 3. Comparison between groups using composite scores.

\begin{tabular}{|c|c|c|c|c|c|c|}
\hline & Groups & Mean & SD & $t$ & $\begin{array}{c}\text { Sig. } \\
\text { (bilateral) } \\
\end{array}$ & $\begin{array}{c}\text { Effect size } \\
\text { (d) }\end{array}$ \\
\hline \multirow{2}{*}{$\begin{array}{l}\text { Learning and } \\
\text { Memory }\end{array}$} & Healthy & 0.798 & 1.325 & \multirow{2}{*}{11.090} & \multirow{2}{*}{$<.001$} & \multirow{2}{*}{1.59} \\
\hline & CPUD & -0.798 & 1.265 & & & \\
\hline \multirow{2}{*}{ Language } & Healthy & 0.349 & 1.869 & \multirow{2}{*}{4.082} & \multirow{2}{*}{$<.001$} & \multirow{2}{*}{0.70} \\
\hline & CPUD & -0.356 & 1.155 & & & \\
\hline \multirow{2}{*}{$\begin{array}{l}\text { Executive } \\
\text { Functions }\end{array}$} & Healthy & 0.463 & 1.746 & \multirow{2}{*}{5.359} & \multirow{2}{*}{$<.001$} & \multirow{2}{*}{0.92} \\
\hline & CPUD & -0.463 & 1.337 & & & \\
\hline
\end{tabular}

CPUD: Individuals with coca paste use disorder. 
Table 4. Final multiple linear regression models for the domains.

\begin{tabular}{|c|c|c|c|c|c|c|c|}
\hline Domains & & B & $\begin{array}{l}\text { Desv. } \\
\text { Error }\end{array}$ & $\beta$ & $\mathbf{t}$ & Sig. & $\begin{array}{c}\text { Adjusted } \\
R^{2} \\
\end{array}$ \\
\hline \multirow{4}{*}{$\begin{array}{l}\text { Learning and } \\
\text { Memory }\end{array}$} & (Intercept) & -0.793 & 0.097 & & -8.207 & $<.001$ & \multirow{4}{*}{.347} \\
\hline & Group & 1.561 & 0.137 & 0.514 & 11.423 & $<.001$ & \\
\hline & Education & 0.031 & 0.031 & 0.062 & 0.990 & .323 & \\
\hline & Group x Edu & 0.163 & 0.045 & 0.230 & 3.657 & $<.001$ & \\
\hline \multirow{4}{*}{ Language } & (Intercept) & -0.348 & 0.114 & & -3.062 & .002 & \multirow{4}{*}{.180} \\
\hline & Group & 0.656 & 0.161 & 0.206 & 4.083 & $<.001$ & \\
\hline & Education & 0.061 & 0.037 & 0.118 & 1.673 & .095 & \\
\hline & Group x Edu & 0.208 & 0.052 & 0.280 & 3.967 & $<.001$ & \\
\hline \multirow{4}{*}{$\begin{array}{l}\text { Executive } \\
\text { Function }\end{array}$} & (Intercept) & -0.452 & 0.111 & & -4.079 & $<.001$ & \multirow{4}{*}{.242} \\
\hline & Group & 0.908 & 0.157 & 0.281 & 5.779 & $<.001$ & \\
\hline & Age & -0.043 & 0.009 & -0.224 & -4.611 & $<.001$ & \\
\hline & Education & 0.180 & 0.026 & 0.341 & 7.034 & $<.001$ & \\
\hline
\end{tabular}


Figure 1. Predicted mean domain ( $\mathrm{Z}$ composite) scores as a function of group and education for Learning and Memory (A), Language (B) and Executive Function (C).
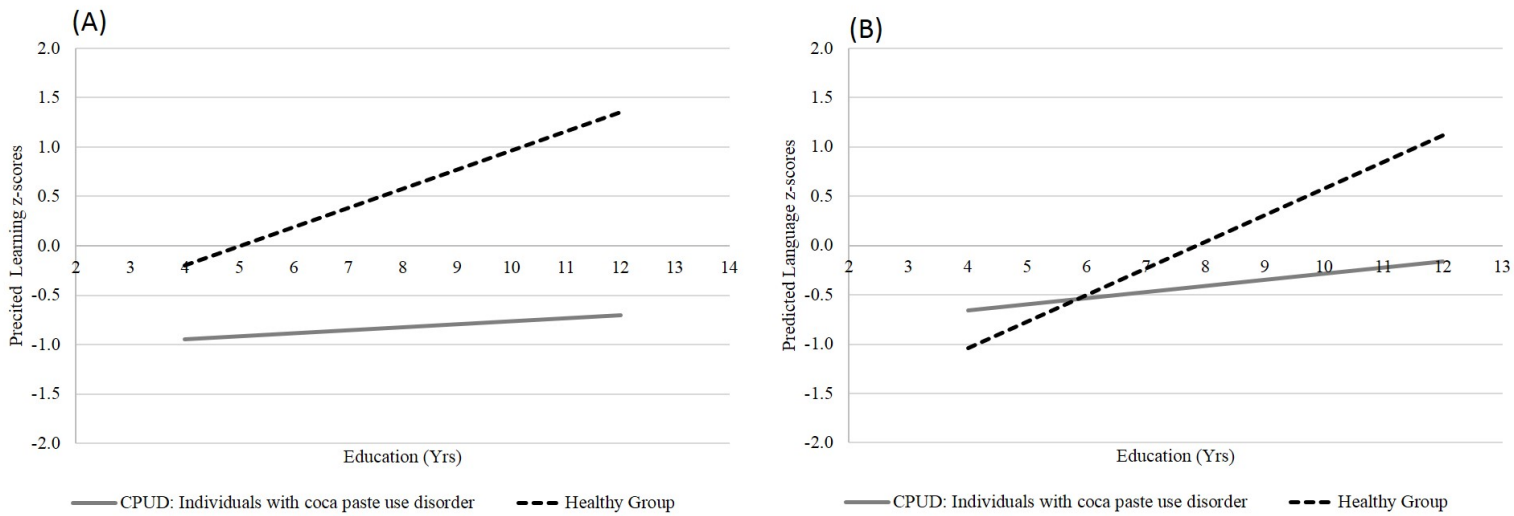

(C)

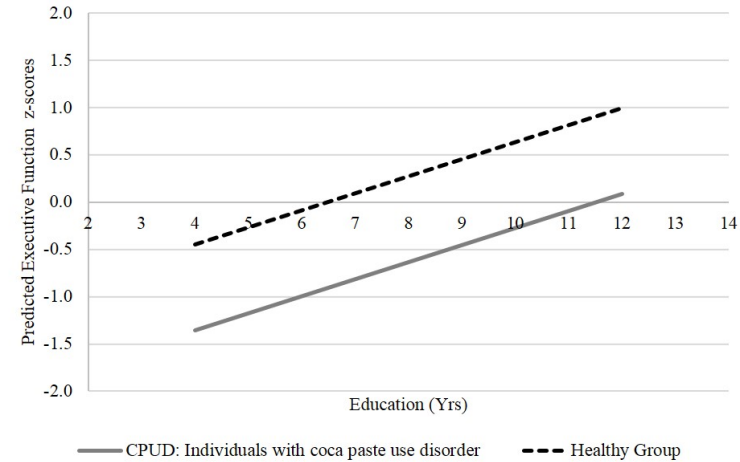

